\title{
Project Guide and Methods Training Manual
}

Ashwin Ravikumar

Martin Kijazi

Anne M Larson

Laura Kowler

With support from

Dawn Rodriguez

Carol Burga

Jazmín Gonzales Tovar

Rodd Myers

Anna Sanders

Anastasia Yang 
Guideline

(c) 2015 Center for International Forestry Research

(c) (i) Content in this publication is licensed under a Creative Commons Attribution 4.0 International (CC BY 4.0), http://creativecommons.org/licenses/by/4.0/

ISBN 978-602-1504-85-7

DOI: $10.17528 /$ cifor/005539

Ravikumar A, Kijazi M, Larson AM and Kowler L. 2015. Project Guide and Methods Training Manual. Guideline. Bogor, Indonesia: CIFOR.

Corresponding author Ashwin Ravikumar - ashwin.r@cgiar.org

CIFOR

JI. CIFOR, Situ Gede

Bogor Barat, 16115

Indonesia

$\mathrm{T}+62(251) 8622-622$

$F+62(251) 8622-100$

E cifor@cgiar.org

\section{cifor.org}

We would like to thank all donors who supported this research through their contributions to the CGIAR Fund. For a list of Fund donors please see: https://www.cgiarfund.org/FundDonors

Any views expressed in this publication are those of the authors. They do not necessarily represent the views of CIFOR, the editors, the authors' institutions, the financial sponsors or the reviewers. 


\section{Contents}

1 Research Training Guide and Researchers' Roles 1

2 Definitions 2

2.1 Multilevel Governance 2

2.2 Procedural Legitimacy 2

2.3 Benefit Sharing 3

3 Background 4

3.1 Research Context 4

3.2 Research Questions: The Big Picture 5

3.3 Approach and Research Framework 6

4 Context, Questions, and Theory 4

4.1 Defining and selecting sites 9

4.2 Identifying Respondents and Capturing Perspectives 11

$\begin{array}{ll}4.3 \text { Guidelines on 'who to interview' } & 11\end{array}$

4.4 Interview instruments 12

$\begin{array}{ll}4.5 & \text { Interview facilitation tips } \\ & 13\end{array}$

$\begin{array}{ll}4.6 & \text { Additional notes on field work } \\ & 13\end{array}$

5 References 15 


\section{Research Training Guide and Researchers' Roles}

This document provides a broad outline of CIFOR's research on Multilevel Governance (MLG) under project funding associated with Reducing Emissions from Deforestation and Degradation (REDD+). The document outlines the key research objectives and methods. Much of the theoretical basis for this research is described by the literature review included as part of this package. The aim of this research is to answer several key questions concerning MLG institutions and land use decisions at the landscape scale, carbon emissions management, and benefit sharing related to different land use changes, including REDD+ initiatives. Studying the research agenda that is outlined in this document will give you the broad context of the CIFOR MLG-REDD+ research. Researchers will use this guide alongside accompanying survey instruments to develop their research protocols for data collection.

This guide is structured as follows. First, definitions of the study's key concepts are provided. Next, the theoretical research questions are discussed, moving from general to specific. For further information on the theory that underpins this investigation, see the literature review and the annexes. Finally, the methodology is described, including site selection and logistics, and specific approaches to data collection. 


\section{Definitions}

This section defines several key terms that are the focus of this research. As research on multilevel governance and land use is, as of 2014, rather exploratory, some of these definitions may change over time. Relatedly, the questions that are most salient for multilevel governance research are likely to evolve.

\subsection{Multilevel Governance}

Multilevel governance (MLG) refers to who makes decisions and how decisions are made by actors operating at multiple levels and scales. Emerson et al. (2012) define MLG broadly as the "processes and structures of public policy, decision-making and management that engage people constructively across the boundaries of public agencies, levels of government, and/or the public, private and civic spheres in order to carry out a public purpose that could not otherwise be accomplished."While other research suggests that multilevel governance may refer to processes and structures that engage people across boundaries in ways that are not necessarily "constructive," and both constructive and less constructive engagements are of interest to MLG scholars, this definition is largely suitable for this research. In other words, this research considers MLG to be about who makes decisions and how decisions are made by actors from across levels and sectors. MLG refers therefore to processes and structures that involve actors from multiple levels, from the local to the national sphere, and also from multiple sectors, including diverse government agencies, NGOs, civil society, and the private sector.
As multilevel governance involves policy, processes, and structures, a thorough understanding requires an assessment of both the legal basis for decision-making by actors from multiple levels and sectors, and analysis of governance in practice. The theoretical framework for this research takes this into account, using multiple data sources to answer these questions, including legal documents and also interviews with actors involved in decision making related to land use. Other definitions of MLG are discussed in the attached literature review, including important critiques that inform many of the questions that drive this research.

\subsection{Procedural Legitimacy}

Based on the literature on collaborative governance, Ansell and Gash (2008) identify several fundamental institutional design features as the "basic protocols and ground rules for collaboration" that they consider critical for the procedural legitimacy of the collaborative governance process. These design principles include: (1) the stakeholders' access to the process itself that emphasizes that the process must be open and inclusive (stakeholder representation); (2) the opportunities for each stakeholder to contribute to decision-making (equal opportunity); and (3) easily accessible and transparent information as well as the clear and consistently applied ground rules that assure stakeholders that the process is fair, equitable, and open (transparency). According to these authors, the process must be open and inclusive because only groups that feel they have had a legitimate 
opportunity to participate are likely to develop a "commitment to the process" (ibid).

Literature also suggests that the legitimacy of the process depends, in part, upon stakeholders' perceptions that they have gotten a "fair hearing"1 (ibid). Clear and consistently applied ground rules reassure stakeholders that the process is fair, equitable, and open. In this way, process transparency means that stakeholders can feel confident that deliberation is genuine. This feature is particularly important considering the power involved in such spaces and the possibility of manipulation (ibid).

Collaborative governance and deliberative democracy scholars both find that developing decisions through deliberation increases the chances that such decisions might be regarded as legitimate by citizens, and thus enhances the possibility of successful implementation and the perceived legitimacy of the system (Mendelberg 2002). As Young (2000) states, the "normative legitimacy" of a democratic decision depends on "the degree to which those affected by it have been included in the decision-making process and have had the opportunity to influence the outcomes" (Parkins and Mitchell 2005; Young 2000, 5-6 as cited in Parkins and Mitchell 2005). Moreover, the main assumption behind deliberative democracy is that democratic political systems "cannot survive without mechanisms securing their legitimacy" (Abels 2007).

In this research we label input legitimacy as procedural legitimacy and output legitimacy as outcome legitimacy. We consider mechanisms of accountability to be critical links between procedural and outcome legitimacy.
Both procedural and outcome legitimacy are normative concepts, as the evaluation of fairness applies both to decision-making procedures (e.g., who should have a say in the decisions) and to the outcomes. Iris Young (2000) and Robert Dahl (1990) explicitly link normative legitimacy to decisionmaking procedures, and claim that normative (procedural) legitimacy implies that all individuals who are affected by a decision are heard and have influence on the decision.

\subsection{Benefit Sharing}

For the purposes of this project, benefit-sharing is defined as the distribution of monetary and non-monetary benefits that flow from a land use change initiative among relevant stakeholders (Luttrell et al. 2013). Benefit sharing arrangements include both formal and informal agreements between stakeholders to share a wide range of direct and indirect benefits. Direct benefit sharing arrangements may include sharing rents, or providing infrastructure for communities, technical support or access to specific forest resources, among many other possibilities. Indirect benefits may include bringing communities into decision making processes, conferring more decision making authority to communities, or strengthening de facto tenure security, among other possibilities. Because REDD+ projects and other benefit sharing arrangements vary widely in terms of substance and context, benefit sharing arrangements are defined broadly to encompass the variety of relevant activities that exist across the areas of study.
1 Fairness requires "the equal distribution of opportunities to act meaningfully in all aspects of the [deliberation] process including agenda setting, establishing procedural rules, selecting the information and expertise to inform the process and assessing the validity of claims" (Ansell and Gash 2008, 557). 


\section{Background Context, Questions, and Theory}

\subsection{Research Context}

This research was conceived as part of CIFOR's Global Comparative Study on REDD+, which began in 2009. The research originally consisted of three research modules, focusing on (1) national REDD+ governance, (2) sub-national REDD+ initiatives including challenges to implementation and livelihoods impacts of projects, and (3) reference levels setting and monitoring, reporting, and verification (MRV). As the first phase of research came to a close and the second phase was being designed, CIFOR researchers realized that there was an important research gap that needed to be filled: the interactions among the array of actors and institutions from the national level to the REDD+ initiatives on the ground. This research module on multilevel governance was conceived to fill this gap, addressing a variety of important research questions related not only to decision-making around REDD+, but also to land use decision making, benefit sharing, and carbon management at the landscape scale. Figure 2 shows the different research modules that are part of the larger Global Comparative Study on REDD+.

As research on REDD+ was conducted, REDD+ projects were implemented on the ground, and REDD+ policies moved forward in sub-national and national jurisdictions, both researchers and policy-makers became increasingly aware of the inherently multilevel nature of REDD+. Moreover, the fundamental conceptual and policy linkages between REDD+ processes and other, broader land use decision making processes became increasingly apparent. It is not possible to understand governance issues related to REDD+ without also understanding how decisions are made related to land use in general, what incentives motivate different actors to make decisions, how power is exercised and maintained in decision-making processes, and how information is shared or controlled in these arenas. These issues have motivated a number of questions that drive this research. These questions, discussed in the subsequent section, are situated at the intersection of several literatures (see literature review). These include, at a minimum, literature explicitly about multilevel governance, a broad body of literature about decentralization, scholarship on common-pool resource management and related notions of polycentric governance, empirical work on community-based forest management and other local natural resource governance, and critical theory on development discourses.

\subsection{Research Questions: The Big Picture}

This research seeks to ask a number of questions about multilevel governance, the politics of land use, and benefit sharing.

How does change occur? Why would an actor with power change land use (or a decision maker promote such a change) to a more sustainable, or lower carbon emissions, option? What are the political obstacles to such changes, and who are the agents of change? What economic obstacles or incentives can motivate low emissions and sustainable development options, 


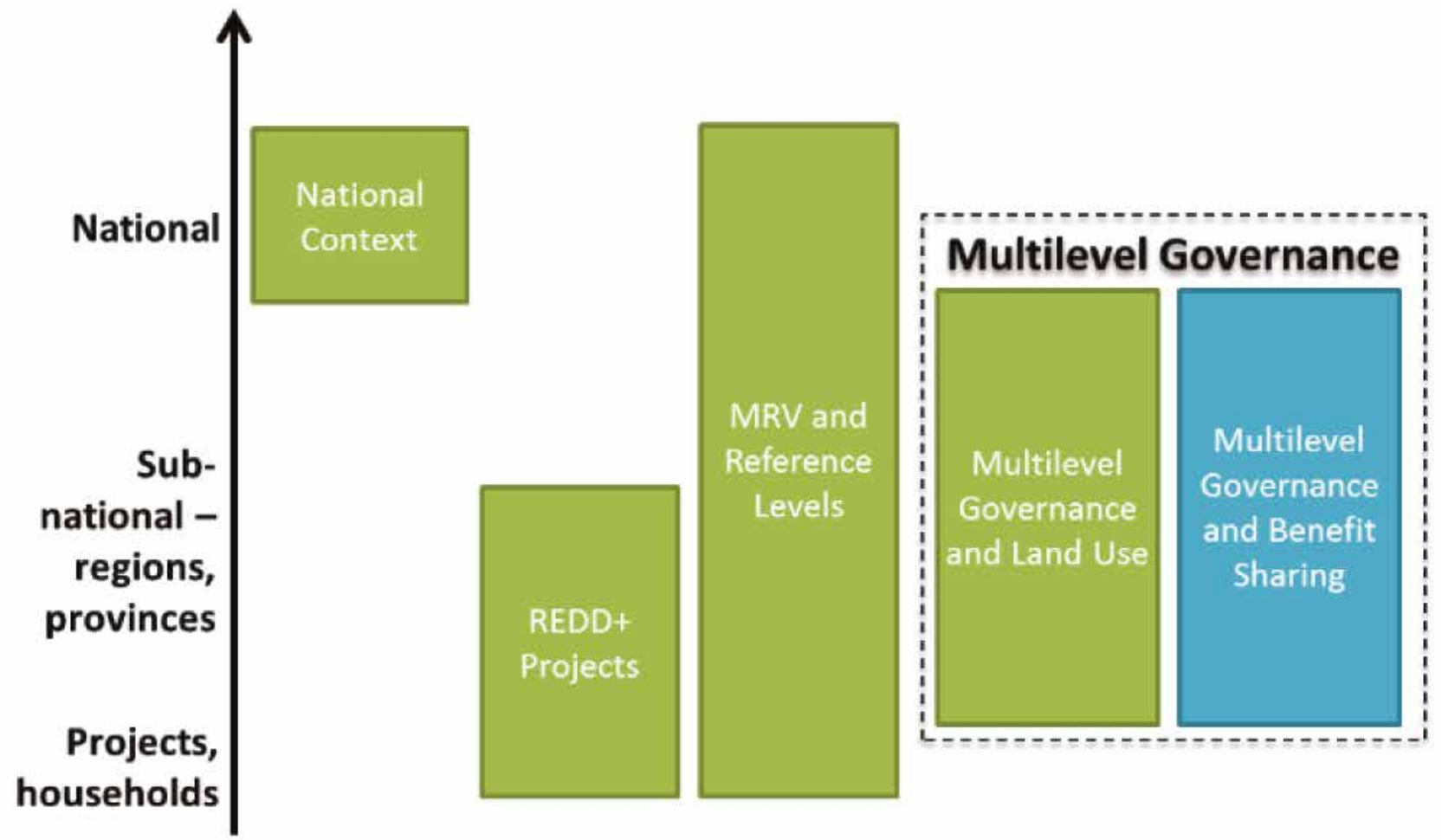

Figure 2. Research Modules of CIFOR's Global Comparative Study on REDD+

or conversely, serve as barriers to such options? Is conservation finance such as REDD+ sufficient, or perceived as sufficient, to offset the opportunity cost of high-emissions development options?

What role do different levels of government play? In areas where emissions are continuing, is anyone trying to change this? If not, why not? If so, who is trying and how? What are the obstacles to success? Are ongoing deforestation and forest degradation-linked initiatives occurring illegally? Or are they planned through legal mechanisms?

The research seeks to understand both the institutions and processes of the decision making arena, and the extent to which processes are legitimate and decision makers are accountable. In assessing legitimacy, we aim to consider the balance of incentives, and how development and conservation objectives compete or work synergistically. Whose behaviors are being targeted by policies? That is, who is causing deforestation and forest degradation, and who is being asked - or obligated - to change their behaviors? How are actors who are changing their behaviors compensated? Are these arrangements perceived as fair? Are such arrangements well understood?

As REDD+ policies and institutions emerge at multiple levels, important questions have been raised about how benefits of REDD+ will be distributed. In this research, we pay particular attention to the multilevel dimensions of benefit sharing, and seek to understand the politics of benefit sharing: how are benefit sharing arrangements designed and implemented? While benefit sharing is often discussed in the context of REDD+, we aim to assess the politics of benefit sharing related to land use change in general. What types of benefit sharing arrangements exist? How have they been created, and who has been involved? How legitimate are these arrangements perceived to be? Have the incentives and institutions generated by REDD+ altered the politics of benefit sharing, or changed the way that benefits are shared? What are the main types of 
benefits from land use that are shared among actors? What accountability mechanisms exist in benefit sharing systems to ensure that all parties to the arrangement comply with their obligations?

As this research is exploratory and based on nonrandomly selected cases, additional questions related to multilevel governance, decision making about land use, and benefit sharing are addressed as they emerge from the case research itself.

\subsection{Approach and Research Framework}

Several methodologies are used in this research to answer some of the multilevel governance research questions described above. Multilevel governance institutions are shaped by laws that assign the distribution of powers and responsibilities related to land use. At the same time, the law itself tells us little about its implementation, and nothing of extra-legal and de facto institutions that are critical for shaping land use governance across levels and sectors.

Figure 3 shows the different data sources that are used in this research, and how they fit together in a broader framework. In our research framework, legal and policy instruments determine high-level incentives and institutions that affect land use. These incentives and institutions are interpreted through and mediated by assemblages of actors from multiple levels and sectors, resulting in specific decisions about land use, and particular arrangements for how benefits from land use are shared. Ultimately, these decisions have both biophysical and socioeconomic impacts, affecting carbon emissions from land use, and livelihoods that depend on the land.

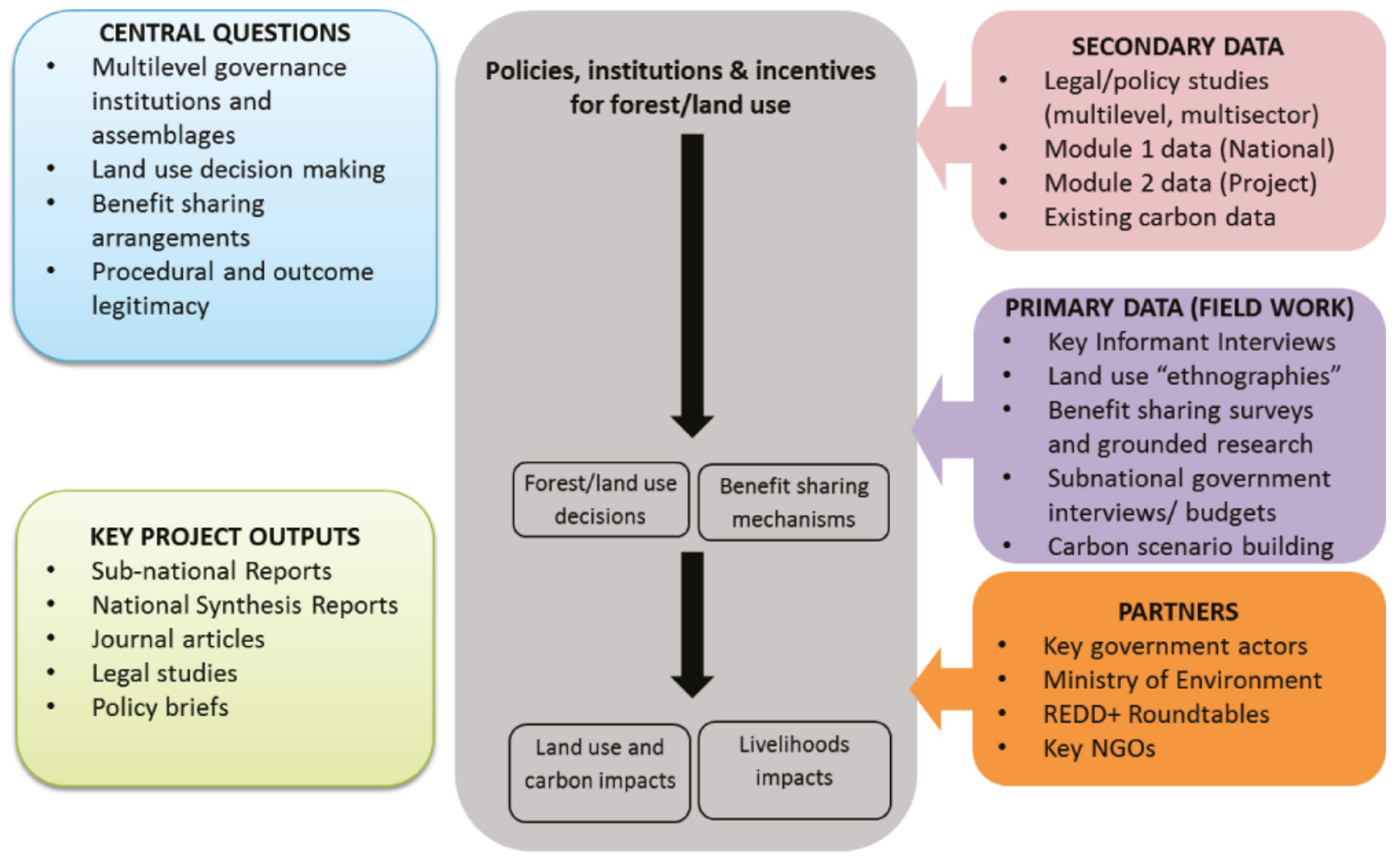

Figure 3. Overall Research Approach and Framework 
The research approach described in this document can be applied anywhere, but as of February, 2015, CIFOR has conducted or is conducting this work in Peru, Indonesia, Tanzania, Vietnam, and Mexico. In each country, a legal study is commissioned to describe the distribution of powers and responsibilities related to land use across levels and divisions of the government. The idea is to understand precisely which government agencies are responsible for what aspects of land use policy and the legal basis of their authority. The concept of a 'multijurisdictional landscape' emerged in the process of conducting this research, an idea used to clarify the notion that land use jurisdictions are complex: there are different agencies from multiple levels that exercise different power and hold different responsibilities across multifunctional landscapes. Figure 4 shows an example of this from data collected in the Madre de Dios region of Peru.

Next, a comparative case study approach involving several study cases from each region is deployed. The methodology for site selection and field research in these case studies is described in the subsequent section. This research generates a suite of outputs between these components, including reports on multilevel governance, land use, and benefit sharing from sub-national regions selected for study, national synthesis reports that bring out cross-cutting themes from multiple sub-national regions within study countries, legal studies that describe the division of powers and responsibilities related to land use in each country, and also policy briefs and journal articles based on the larger outputs. As case study work is conducted in partnership with boundary partner organizations, it is essential that researchers spend meaningful efforts in building relationships with local and national organizations that are in a position to take up research outputs, and utilize key findings and recommendations.

Theoretically we consider the existence of multiple governance arrangements including: (1) democratic representation, where policy arrangements are negotiated via democratic channels; (2) nested or polycentric institutions - where policy is driven from above, but multiple levels of institutions below work in tandem with those above them; (3) legal pluralism - which recognizes both formal and informal institutions, where policy is driven mostly from below; (4) deliberative networks and institutions, which involve open discussions and participation among stakeholders; (5) cross-sector partnerships involving different actors, with different levels of influence and power, who come together to implement policy (Forsyth 2009).

In order to understand the realities of multilevel governance, including how they may fit into this typology, field work is carried out at several sites in each region of study. The following sections describe the approach to field work in detail. 


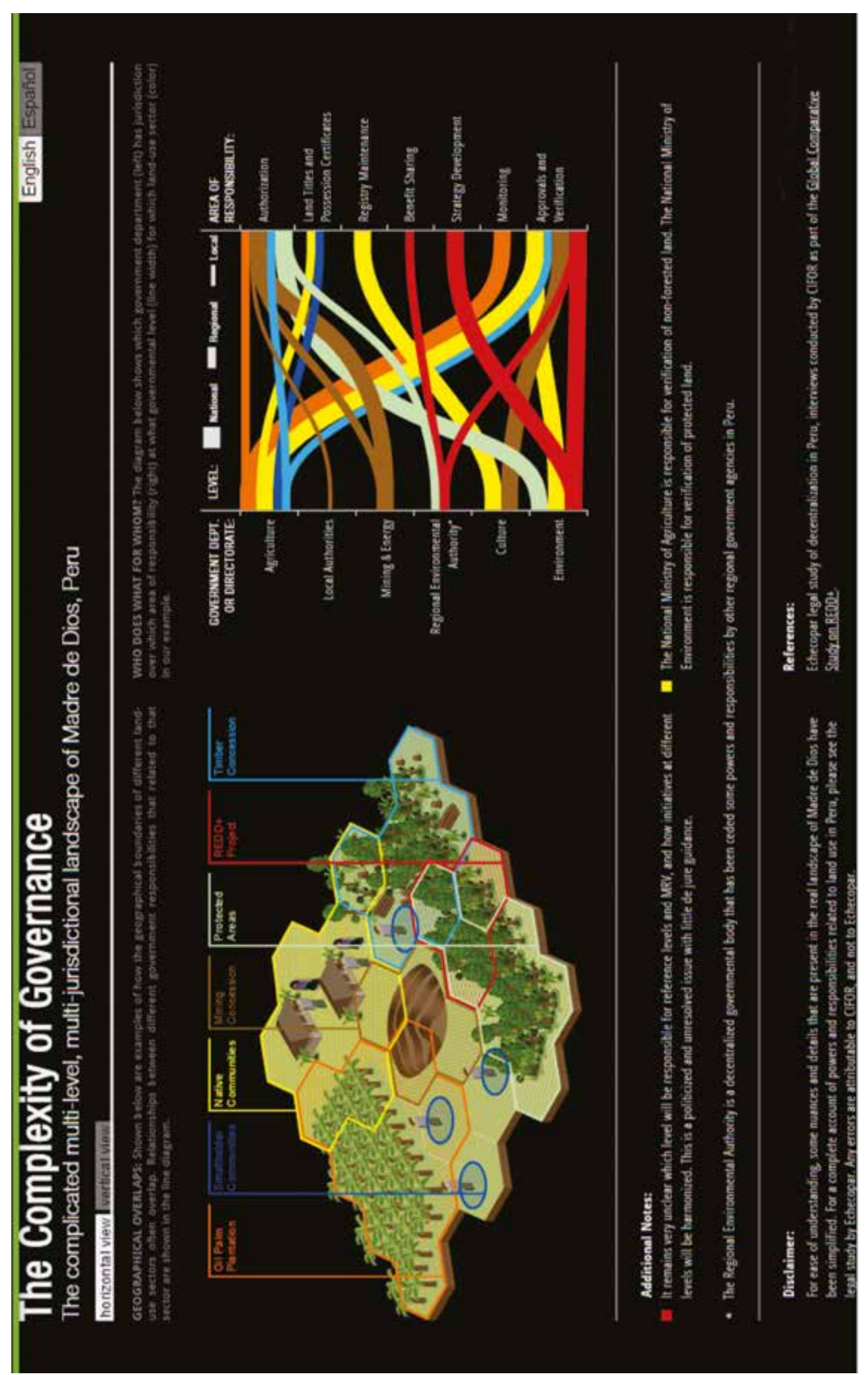

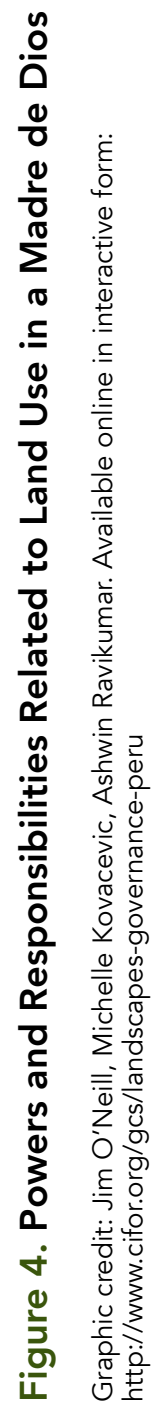




\section{Field work methods}

\subsection{Defining and selecting sites}

The goal of this approach is to permit research that is both exploratory - that is, compatible with grounded theory and capable of allowing respondents and stakeholders to define key themes and generate questions, rather than imposing rigid hypotheses from the beginning of the research - and also global and comparative, amenable to meaningful comparisons across contexts. Achieving both of these aims is methodologically challenging. To accomplish this, we utilize a comparative case study approach; the particular definitions of the terms 'site' and 'case' are important to understand.

Research sites are defined as specific, well defined areas, with a particular and identifiable past land use change, or an existing initiative to change land use. In each area of study, researchers select two sites where land use change has resulted in, or is likely to result in, increased carbon emissions from land use. Such initiatives may include conversion of primary forest to plantations such as oil palm or timber, forest degradation due to logging, new or expanding mining activities, or agricultural expansion.

In addition, three sites should be selected where land use change has moved towards decreasing carbon emissions uses, or there are plans to move towards lower emissions land uses. Such sites may include sustainable community-based forest management, forest certification initiatives, conversion of coffee or cacao plantations to agroforestry systems, expanding conservation areas, or reforestation. These changes may be supported by REDD+ projects, payments for environmental services schemes, or other policies. As understanding REDD+ in particular is an important focus of this research, researchers should ensure that several sites in each country are indeed linked to REDD+ initiatives. At the same time, non-REDD+ sites should also be included in order to facilitate comparisons and to understand the degree to which REDD+ is responsible for changes that are observed on the ground. Figure 5 shows the site selection approach visually.

In CIFOR research on multilevel governance as of 2015, special efforts have been made to include REDD+ sites where other CIFOR researchers have conducted studies on livelihoods impacts of projects, so that multilevel governance structures and livelihoods impacts can be analyzed jointly in future work.

Site selection is not random, but should be coordinated to capture a set of land use change initiatives that plausibly represent broader changes and other initiatives that are occurring in the study region. Increasing emissions sites should, for example, be chosen based on the main drivers of deforestation in the study region. If oil palm expansion is a key driver of deforestation in the region, then it should be a priority, for example. In a region with high mining impacts, sites of mining intensification or expansion should similarly be given strong consideration. Information about the drivers of deforestation and forest degradation should be ascertained from existing research and secondary sources, and interviews with key informants in the study region if necessary. In addition, researchers with experience working in the study 


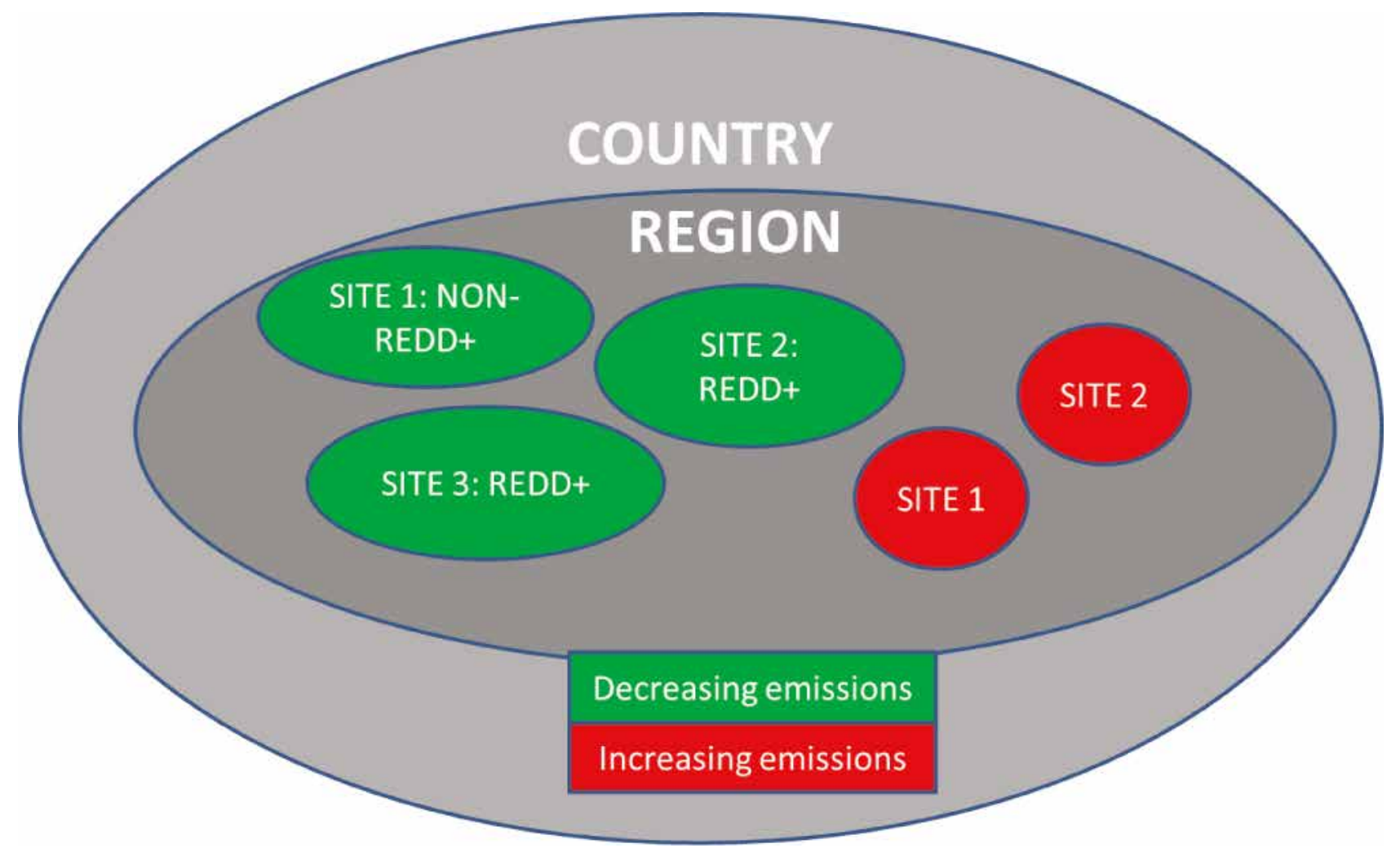

Figure 5. Site selection strategy

regions have been deliberately contracted to ensure that the team has an internalized understanding of the study contexts, including drivers of deforestation and forest degradation.

Decreasing emissions sites should be selected with the following criteria in mind:

1. Ensure that some REDD+ initiatives are represented

2. Benefit sharing arrangements should exist in some of the sites. This has been difficult to ensure in practice, because relatively few REDD+ initiatives had well defined benefit sharing arrangements when CIFOR began this research in 2013.

3. At least two sites should have carbon data available, as CIFOR has been conducting workshops on future scenario building utilizing partnerships established through this research. Carbon modeling based on future scenarios of land use developed by actors from multiple levels and sectors with an interest in, or influence over, landscapes under study is conducted in these workshops. Having data on land cover and carbon at two sites in each country makes it much easier to facilitate these workshops.

In both the sites of increasing and decreasing emissions, the following criteria should be considered:

1. There must be a rural population that is affected remote protected areas should not be prioritized.

2. A variety of multilevel governance arrangements should exist: minimally, locations where local governments are more and less involved in land use decision making should be included where possible.

3. Logistics, including cost, access, and the availability of a social license to operate, must be considered.

The 'case,' which is ultimately the object of study in each case study, is distinguished from the 'sites' described above because multilevel governance research necessarily involves actors and institutions that exist and operate beyond the confines of the site of land use change. In the context of this research, the 'case' therefore refers to the complete assemblage of actors, 
institutions, and policies, from the national level to the 'site' that influence, mediate, and constrain the decision processes and that have led to the land use change under study. Researchers' reports should describe each case with attention to this entire assemblage, not limited to the site of land use change itself, or necessarily to any particular jurisdiction. Rather, all actors, institutions, and policies, from all relevant jurisdictions, should be included in the multilevel governance analysis.

\subsection{Identifying Respondents and Capturing Perspectives}

The researcher's degree of familiarity with the study region will determine the amount of scoping activities that must be done in order to complete site selection. In general, the first step is to identify and interview key informants in the regional capital to understand the main land use changes that are occurring, or are being planned. Such key informants are likely to be housed in regional governments, research institutes, or important NGOs that operate at the regional level.

Once sites have been identified according to the criteria described above, a snowball sampling procedure is used to capture key perspectives from actors with an interest in, or influence over, the decision process. Beginning at the regional level, actors involved in the initiative should be interviewed. Further interviews should then be conducted with actors who are directly involved with the site itself. Who these actors are depends on the nature of the site, and researchers should take measures to ensure that all relevant perspectives on the sites are captured.

Given the snowball sampling approach, and the fact that it is not always feasible to conduct a random sample of all stakeholder groups who may have an interest in or influence over the land use change, it is necessary to take special measures to ensure that as many perspectives as possible are captured. For REDD+ projects, for example, proponent NGOs are often key facilitators of research and gatekeepers. There may be communities, or members of communities, that these facilitators are not as well connected to, or who participated less in the design and implementation of the land use change initiative or associated benefit sharing arrangement. Researchers should aim to interview representatives from groups that may be affected by land use changes or benefit sharing arrangements, but may not have been involved in the decision or policy design process. If researchers have reason to believe that some groups or individuals were excluded from decision processes, it is important to capture their perspectives as well, to the extent that it can be done safely and with respect to local norms and agreements with local partners.

The research instruments include an 'articulation' section designed to explicitly elicit information about which perspectives are important, and which actors have been involved in decision-making related to the land use change under study, or have been affected by the change. This tool should be used by researchers to understand and characterize the assemblage of actors involved in and affected by decisions related to land use and associated benefit sharing arrangements, and also to facilitate further interviews with relevant actors.

\subsection{Guidelines on 'who to interview'}

While the specific actors that should be contacted vary from case to case, there are some guidelines and rules of thumb that are useful:

1. It is usually necessary to conduct at least ten key informant interviews at the regional level. These key informants should represent a mix of sectors and interests, including important NGOs and the regional government. If there are multiple departments within the regional government that are influential, or have legal powers, researchers should ensure that all of them are contacted. Ensure that all potentially relevant divisions of the regional government are captured. For example, even if the environmental or natural resources division is most involved in regional REDD+ processes and discussions, the researcher should still make sure to interview representatives of the agricultural, mining, or planning divisions, if they are relevant.

2. Local governments vary in their degree of involvement in land use and REDD+. Even if it is fairly well understood that local governments play 
a limited role in these processes, they should be interviewed to capture their perspectives.

3. Civil society organizations such as farmers' associations, co-ops, unions, indigenous peoples groups, and religious groups, may have strong or weak links with the government and key NGOs. Researchers should make an explicit effort to capture their perspectives, as they often have a stake in land use regardless of whether they participate in the same decision making arenas as government actors.

4. Community leaders should be interviewed to the extent that it is possible. Some land use initiatives may affect many communities. It is outside the scope of this research to conduct random household surveys in all communities affected by the landscapelevel land use changes under study. At the same time, researchers should make sure that community perspectives are captured. To the extent that there is variation in the degree to which different communities have participated in land use decision making, or are involved in REDD+ initiatives, these diverse community perspectives should be captured. It is reasonable to interview a handful of farmers and community members, although researchers should take care not to present non-randomly selected community perspectives as representative.

5. Cases vary in their complexity, and in the degree to which they are characterized by conflict. More interviews are necessary in cases with more conflicted perspectives, while less are necessary in cases with a clearer consensus. A rule of thumb, based on research to date, is that at least ten interviews are necessary for cases. Often, a particularly strong key informant will be a rich source of information, and researchers may interview them multiple times to gain further depth of understanding. While the interview instruments described below are designed to permit interviews that last an hour or less, in many cases, conversations that last far longer than an hour - due to the enthusiastic desire of the respondent to continue to converse with the researcher - can be critical sources of data.

6. While this research on multilevel governance tends to take sub-national jurisdictions as a starting point, national policies, actors, and institutions very often play key roles in land use governance and politics.
To the extent that perspectives from the national level are necessary to gain a complete picture of the region, or a particular case, researchers should include them.

\subsection{Interview instruments}

The methods for the field studies aim to acquire information about specific land use changes towards both higher and lower carbon emissions, understand the design and management of benefit sharing arrangements, and ascertain relationships between and within assemblages of actors who influence land use.

The field research focuses on multiple sub-national levels and also their links to the national level and to 'communities.' However, interviews are conducted more extensively and intensively at the sub-national level. Other components of CIFOR's Global Comparative Study on REDD+ have conducted or are conducting more indepth research at the national and community levels.

Simply put, we want to understand what land use decisions are made, why they are made, and how they are made, including the role of REDD+ proponents in land use decision processes. In the attached interview guide, there are three components:

1. A guide for interviewing key informants at regional and local levels. The aim of this instrument is to understand land use in a region, province, or district, and also to ascertain information about specific land use changes. This tool can be utilized during the site selection process, to understand which sites are most suitable for multilevel governance research, and also after sites are selected, to gain perspectives from key informants about selected sites.

2. A question guide that should be used as a reference during interviews focused on a detailed descriptive historical understanding of land use history, conflict, and politics.

3. An interview/survey guide for key informants on benefit sharing - i.e. actors highly knowledgeable of the processes - aiming to bring out experiences and perceptions of the benefit sharing process. This includes respondents' perceptions of equity, legitimacy, and fairness of benefit sharing arrangements. 
These guides are included in this folder in a single document divided into three sections. Because they are designed to be free-standing individually, some sections are repeated. If more than one questionnaire is to be used with a single informant, however, this repetition should of course be avoided. Elements of the three guide components may also be combined by researchers if the information needed from a particular respondent cuts across the multiple components.

\subsection{Interview facilitation tips}

As these instruments are guides, and not rigid questionnaires, researchers should utilize them to gain insights into the key concepts and questions that are described in this document, as well as with an eye to conducting the analyses that the attached report template call for. There are several important suggestions for researchers using these instruments, summarized below.

- $\quad$ Familiarize yourself with the big-picture questions, and have an intuitive sense of the empirical and theoretical questions you want to answer for your case, or for the region as a whole.

- Go into each interview with an agenda, but keep your agenda flexible. Have a sense of what perspective you hope your respondent will add to your existing data on the case - and then prepare to be surprised.

- While you should be familiar with and thinking about the big picture questions, also make sure that you are extremely familiar with the questions formulated in the guides. These guides are important tools and have been written to include questions that elicit responses that connect to the bigger themes.

- Maintain a conversational approach, and avoid being adversarial. Use the questions in the guide, and take advantage of your familiarity with the guides to steer responses to one question towards other questions in the guide in a way that works with rather than against the flow of the conversation.

- Be aware of politicized issues and topics that are tied to conflict, or are otherwise sensitive. At the same time, do not avoid these issues unduly, or shy away from these topics entirely. They are essential parts of this research, and often respondents will surprise you in their willingness to discuss topics that you had believed to be highly sensitive. It is possible that respondents will prefer not to discuss some topics - but unless there's a good reason, researchers should not preemptively forfeit such conversations altogether!

\subsection{Additional notes on field work}

1. In relation to each site where these changes have occurred or are occurring, actors to be interviewed will be determined deliberately based on their knowledge of land-use decision or benefit sharing processes (i.e. key informants). However, others will be identified in the field through snow-ball sampling, following interviews with predetermined key informants (as part of the articulation questions). Some actor mapping prior to commencement of extensive field work may help in this process.

2. Note the need to work with the government, as this project is aimed at working to improve policy and policy implementation across scales. The research must include key actors involved in low/high carbon emissions land use decision making and benefit sharing processes at regional and local levels. But this should include both government agencies and relevant non-governmental actors. Whether or not local governments have or appear to have a key role in land use decisions, interviews must be conducted with local government actors in each jurisdiction where these sites are located (or at least one key jurisdiction if the site crosses more than one).

3. Alongside this methods guide, there is a separate interview questions guide based on key hypotheses and relationships developed in this document.

4. Many of the questions in the aforementioned interview questions guide suggest responses that could be used by the researcher during an interview or after the interview to help classify responses. Responses to closed survey questions should be noted during the interview. All discussion and responses to open ended questions should be recorded in notes.

5. All quantitative and qualitative data will subsequently have to be recorded in Nvivo. A guide to the nodes used for coding data in Nvivo is attached.

6. Researchers will prepare a report following the template provided as a supplement. 


\section{Supplemental documents}

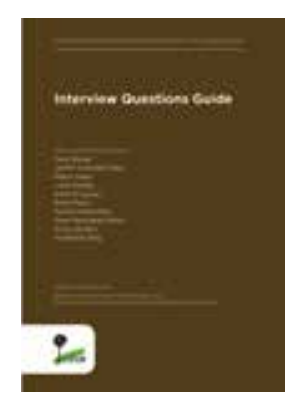

CIFOR. 2015. Interview Questions Guide. Guideline. Bogor, Indonesia: CIFOR.

DOI: $10.17528 /$ cifor/005540

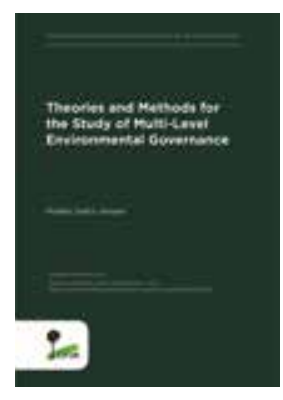

Saito-Jensen M. 2015. Theories and Methods for the Study of Multi-Level Environmental Governance. Guideline. Bogor, Indonesia: CIFOR.

DOI: 10.17528/cifor/005541

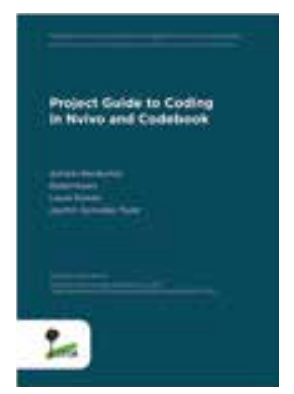

Ravikumar A, Myers R, Kowler L and Tovar JG. 2015. Project Guide to Coding in Nvivo and Codebook. Guideline. Bogor, Indonesia: CIFOR.

DOI: $10.17528 /$ cifor/005542 


\section{References}

Abels G. 2007. Citizen involvement in public policy-making: Does it improve democratic legitimacy and accountability? The case of PTA. Interdisciplinary Information Sciences 13:103-116.

Ansell C and Gash A. 2008. Collaborative governance in theory and practice. Journal of Public Administration Research and Theory 18:543-571.

Dahl RA. 1990. After the revolution?: authority in a good society. Yale University Press.

Emerson K, Nabatchi T and Balogh S. 2012. An integrative framework for collaborative governance. Journal of Public Administration Research and Theory 22:1-29.

Forsyth T. 2009. Multilevel, multiactor governance in REDD+: Participation, integration and coordination. Bogor, Indonesia: CIFOR.
Luttrell C, Loft L, Gebara MF, Kweka D, Brockhaus M, Angelsen A and Sunderlin WD. 2013 Who should benefit from REDD+? Rationales and Realities. Ecology and Society 18:52.

Mendelberg T 2002. The deliberative citizen:

Theory and evidence. Political decision making, deliberation and participation 6:151-193.

Parkins JR and Mitchell RE. 2005 Public participation as public debate: a deliberative turn in natural resource management. Society and Natural Resources 18:529-540.

Young IM 2000. Inclusion and democracy. Oxford University Press. 


\begin{tabular}{|l|l|l|} 
RESEARCH & $\begin{array}{l}\text { This research was carried out by CIFOR as part of the CGIAR Research Program on Forests, Trees } \\
\text { and Agroforestry (CRP-FTA). This collaborative program aims to enhance the management and } \\
\text { PROGRAM on }\end{array}$ \\
$\begin{array}{l}\text { Forests, Trees and } \\
\text { Agroforestry }\end{array}$ & $\begin{array}{l}\text { use of forests, agroforestry and tree genetic resources across the landscape from forests to farms. } \\
\text { CIFOR leads CRP-FTA in partnership with Bioversity International, CATIE, CIRAD, the International } \\
\text { Center for Tropical Agriculture and the World Agroforestry Centre. }\end{array}$ \\
\hline CGIAR
\end{tabular}

\section{Norad}

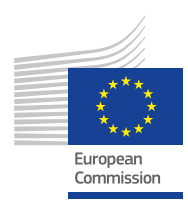

(n)

\section{Center for International Forestry Research (CIFOR)}

CIFOR advances human well-being, environmental conservation and equity by conducting research to help shape policies and practices that affect forests in developing countries. CIFOR is a member of the CGIAR Consortium. Our headquarters are in Bogor, Indonesia, with offices in Asia, Africa and Latin America. 